\title{
Aquarium Water Quality Monitoring Based On Internet Of Things
}

\section{Monitoring Kualitas Air Akuarium Berbasis Internet Of Things}

\author{
Bima Setya Kusumaraga $^{* 1)}$, Syamsudduha Syahrorini' ${ }^{2)}$, Dwi hadidjaja ${ }^{3)}$, Izza Anshory ${ }^{4)}$ \\ \{emailgudang10@gmail.com, syahrorini@.ac.id.\}
}

Program Studi Teknik Elektro, Jurusan Teknik Elektro Universitas Muhammadiyah Sidoarjo

\begin{abstract}
Guppy fish is one type of ornamental fish that is widely kept in aquariums. Water temperature, water pH, and water turbidity are important factors for the life and development of guppy fish in an aquarium. The ideal water conditions for guppy fish in the aquarium are 23-27oC, a pH value of 6.5-7.5, and a water turbidity level of 0-25 NTU. To maintain ideal water conditions, research is needed to keep the aquarium water conditions stable. The research was conducted by experimenting using the NodeMCU platform as a microcontroller and the DS18B20 temperature sensor for sensing water temperature, a pH sensor 4502C, and a TDS sensor for sensing water turbidity. Testing is done by detecting the condition of the aquarium water with all sensors simultaneously to find out the water conditions in real time. The test results show that the tool designed is able to maintain water temperature at 23-27 $o C$, maintain pH values at 6.5-7.5, and water turbidity at 0-25 NTU. Thus the tool is able to maintain the ideal aquarium water quality for guppies.
\end{abstract}

Keywords - wate; temperatur; $\mathrm{pH}$; turbidity

\begin{abstract}
Abstrak. Ikan guppy adalah salah satu jenis ikan hias yang banyak dipelihara di akuarium. Suhu air, pH air, dan kekeruhan air adalah factor penting hidup dan berkembangnya ikan guppy dalam akuarium. Kondisi air yang ideal untuk ikan guppy dalam akuarium yaitu memiliki suhu 23-27oC, nilai pH 6,5-7,5, dan tingkat kekeruhan air 0-25 NTU. Untuk menjaga kondisi air yang ideal perlu dilakukan penelitian untuk menjaga kondisi air akuarium tetap stabil. Penelitian dilakukan dengan eksperimen menggunakaan platform NodeMCU sebagai mikrokontroller dan sensor suhu DS18B20 untuk penginderaan suhu air, sensor pH 4502C, dan sensor TDS untuk penginderaan kekeruhan air. Pengujian dilakukan dengan cara mendeteksi kondisi air akuarium dengan semua sensor secara bersamaan untuk mengetahui kondisi air secara realtime. Hasil pengujian menunjukan bahwa alat yang dirancang mampu untuk mempertahankan suhu air pada suhu 23-27 oC, mempertahankan nilai pH pada 6,5-7,5, dan kekeruhan air pada 0-25 NTU. Dengan demikian alat mampu menjaga kualitas air akuarium yang ideal untuk ikan guppy.
\end{abstract}

Kata kunci - air; suhu; $p H$; kekeruhan

\section{PENDAHULUAN}

Ikan guppy yaitu jenis ikan yang lazim dipelihara pada akuarium sebagai penghias ruangan. Kondisi air akuarium sangat berpengaruh pada kehidupan dan perkembangan ikan guppy. Karena pentingnya kondisi air untuk ikan guppy maka dilakukan penelitian untuk mempertahankan kondisi air yang ideal untuk ikan guppy. Terutama pada suhu air, nilai $\mathrm{pH}$ air, dan kekeruhan air[1].

Penelitian ini bertujuan mengontrol dan memonitoring kondisi air akuarium. Pengontrolan dilakukan dengan 3 sensor, suhu, kekeruhan dan $\mathrm{pH}$. Untuk pengkondisian suhu air pada alat menggunakan range 23-27 derajat celcius. Jika suhu air diluar suhu tersebut maka kipas dan heater akan mengkondisikan suhu air. Untuk kekeruhan memiliki range 0-25 NTU, jika kekerihan air diluar dari range tersebut maka pompa air akan menyala untuk melakukan penyaringan[2]. Untuk pengkondisian $\mathrm{pH}$ air memiliki range 6,5 - 7,5. Penelitian ini menggunakan sensor suhu DS18B20, sensor kekeruhan air TDS, dan sensor pH 4502C. Dengan prinsip kerja sistem, jika nilai pH diluar dari nilai tersebut maka pompa akan bekerja untuk melakukan sirkulasi air dengan batu zeolite untuk mengkondisikan nilai pH. Jika kondisi suhu, pH dan kekeruhan air masuk pada kondisi ideal maka pompa, heater, dan kipas hanya bersifat stand by. Alat ini diharapkan membantu kualitas air akuarium ikan guppy pada stabilitas suhu, PH dan kekeruhan sesuai kebutuhan ikan guppy, agar ikan guppy dapat berkembang dengan baik.

\section{Ikan Guppy}

Ikan guppy (Poecilia reticulata) yaitu ikan yang lazim ditemukan di Indonesia. Ikan guppy termasuk ikan yang sangat mudah berkembang biak sehingga bisa ditemukan di sungai Indonesia. Ikan guppy memiliki masa simpan telur sekitar 28 hari[3]. 
Ikan guppy salah satu kategori ikan air hangat yang biasa hidup pada suhu diatas 20 oC. suhu ideal yang bisa membuat ikan guppy berkembang dengan baik adalah 23-27 oC. toleransi kekeruhan ikan air hangat lebih tinggi dari ikan air dingin. Ikan air dingin memiliki toleransi kekeruhan air sebesar 0-10 NTU sedangkan ikan air hangat memiliki nilai toleransi 0-25 NTU. Ikan guppy bisa hidup pada kondisi air basa maupun asam dengan kisaran derajat keasaman 5-11 pH. Tetapi ikan guppy lebih aktif dan memiliki perkembangan yang lebih baik pada kondisi air basa atau netral. Ikan guppy sangat cocok berkembang biak pada $\mathrm{pH}$ 6,5-7,5[4].

\section{Sensor}

Pada penelitian alat ini menggunakan 3 jenis sensor yang berbeda untuk mendeteksi kondisi air. Sensor yang digunakan yaitu sensor suhu DS18B20, sensor kekeruhan air TDS, dan sensor pH 4502C. penggunaan 3 sensor untuk menunjang tingkat keberhasilan alat untuk mendeteksi dan menjaga kondisi yang ideal untuk ikan guppy.

Untuk pengindraan suhu air menggunakan sensor DS18B20. Sensor suhu DS18B20 memiliki 3 pin yaitu vcc, ground dan data. Sitem kerja sensor suhu yaitu memngirimkan tegangan ke air dan menerimanya kembali yang kemudian dikonversi menjadi satuan suhu berdasarkan tegangan balik yang diterima[5][6].

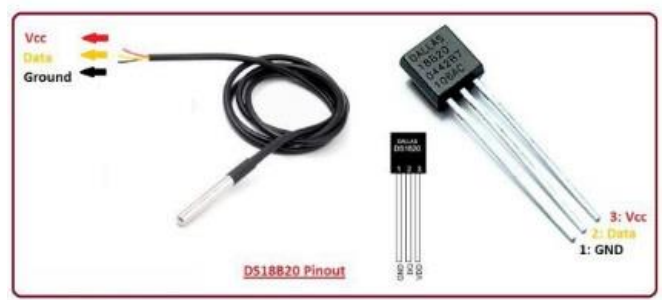

Gambar 1. Sensor suhu DS18B20[5]

Sensor kekeruhan yang digunakan adalah sensor TDS (Sensor Total Dissolve Solid). Sensor TDS adalah sensor yang bisa membaca zat padat yang bercampurdengan air sehingga bisa digunakan untuk mendeteksi tingkat kekeruhan air. Cara kerja sensor TDS yaitu dengan memberikan tegangan input sebesar 3,3-5 Volt kemudian memasukkan probe pada air yang akan diukur dan menghitung nilai tegangan output pada pin TDS[7]. Semakin tinggi nilai tegangan output maka air semakin jernih dan sebaliknya. Untuk menghitung tingkat kekeruhan air atau biasa disebut Nephelometric Turbidity Unit (NTU) kita bisa menggunakan rumus $\mathrm{y}=(-26,7624) \mathrm{X}+135,0524$, $\mathrm{X}$ yaitu nilai voltase TDS. WHO menyatakan nilai air yang bening ada pada range 0-5 NTU, jika lebih dari 5 NTU maka air dinyatakan dalam keruh keruh[8].

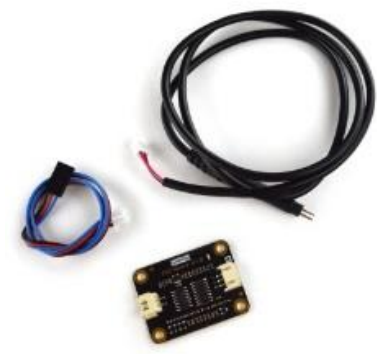

Gambar 2. Sensor TDS (Total Dissolve Solid) [8]

Sensor pH yang digunakan adalah 4502C. sensor $\mathrm{pH}$ termasuk dalam sensor besaran kimia yaitu mengubah besaran zat kimia menjadi besaran listrik. Sensor ph 4502C memiliki 2 elektrode, yaitu electrode kaca dan refrensi. Elektroda kaca berfungsi mengukur ion yang terlarut dalam air sedangkan elektroda refrensi berfungsi mengkonversi nilai yang dibaca oleh electrode kaca menjadi besaran listrik. Semakin banyak nilai ion yang terdeteksi maka semakin asam air yang diukur[9].

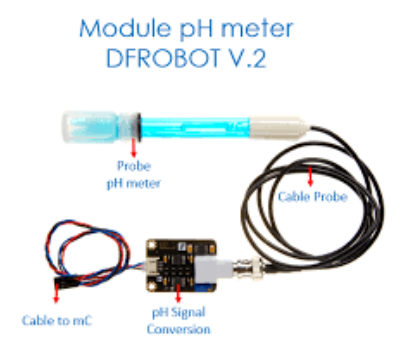

Gambar 3. Sensor pH 4502C[9] 
Procedia of Engineering and Life Science Vol. 1. No. 2 Juni 2021

Seminar Nasional \& Call Paper Fakultas Sains dan Teknologi (SENASAINS 2nd)

Universitas Muhammadiyah Sidoarjo 


\section{Mikrokontroller dan Internet of Things}

Internet of Things adalah pengembangan teknologi yang menggunakan jaringan internet untuk transfer data tanpa perlu ada interaksi secara langsung antar manusia atau manusia dengan computer. Cara kerja system IoT adalah dengan mengkombinasikan dengan system pemrograman mikrokontroller. Program yang tersimpan pada mikrokontroller akan diterjemahkan oleh IoT dan IoT akan memproses data sesuai dengan program yang tersimpan pada mikrokontroller[10].

Mikrokontroller adalah rangkaian platform yang digunakan untuk menyimpan pemrograman yang kita coding pada computer sekaligus untuk menjadi actuator pemrograman yang kita simpan pada platform tersebut[11].

Platform yang digunakan adalan NodeMCU, platform NodeMCU adalah salah satu platform yang support untuk pengaplikasian internet of things[7]. NodeMCU menggunakan coding scripting Lua. Sistem kerja NodeMCU mirip dengan arduino yaitu dengan membaca program yang telah d compile pada NodeMCU untuk memberi atau memutus tegangan pada pin yang tersedia dengan tambahan fotur yang bisa langsung tersambung dengan jaringan wifi[12][13].

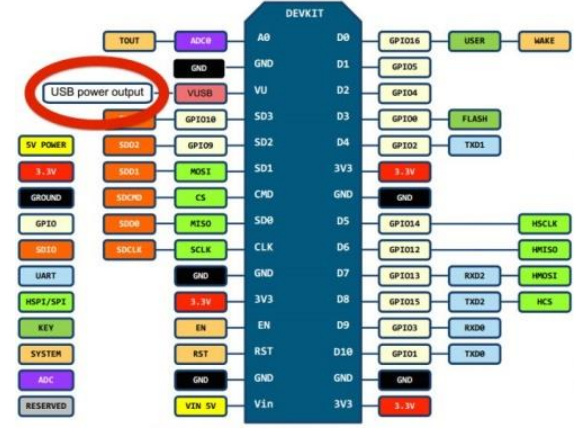

Gambar 4. Diagram Blok NodeMCU[12]

\section{METODE PENELITIAN}

Penelitian ini merupakan penelitian eksperimen dengan merancang dan membuat alat ukur kualitas air akuarium berbasis IoT, dengan menggunakan tiga sensor yakni sensor suhu DS18B20, sensor kekeruhan air TDS, ketiga sensor ini diharapkan menjaga kondisi yang ideal untuk ikan guppy. Perancangan alat dapat ditunjukkan pada blok diagram berikut:

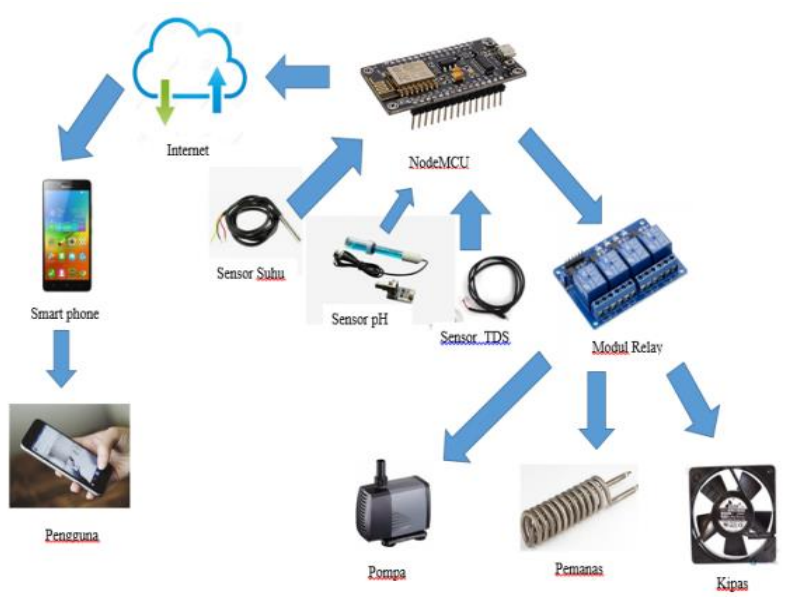

Gambar 5. Diagram Blok Alat

Cara kerja alat jika dilihat dari diagram blok diatas yaitu sensor melakukan pendeteksian lalu mengirimkan sinyal ke nodeMCU. Sinyal yang diterima akan diolah sesuai program yang di compile. Kemudian nodemcu akan memberikan input ke relay untuk menjalankan pompa, kipas, dan heater.

Data yang diambil pada pengujian alat ini yaitu untuk mengetahui dan menjaga kualitas kondisi air akuarium ikan guppy secara realtime menggunakan tiga sensor yang memiliki karakteristik berbeda. Pengujian dilakukan menggunakan platform NodeMCU.

Pengujian dan pengambilan data yaitu dengan metode :

Pengujian pertama untuk menguji kestabilan setiap sensor dengan cara dilakukan uji coba terpisah pada setiap sensor yang digunakan. 
Procedia of Engineering and Life Science Vol. 1. No. 2 Juni 2021

Seminar Nasional \& Call Paper Fakultas Sains dan Teknologi (SENASAINS $2^{\text {nd }}$ )

Universitas Muhammadiyah Sidoarjo

Pengujian kedua yaitu menguji system kerja alat secara keseluruhan, yaitu dengan menjalankan alat dengan menggunakan semua sensor yang ada untuk mendeteksi kondisi air akuarium ikan guppy.

\section{HASIL DAN PEMBAHASAN}

Uji coba alat dilakukan dengan dua cara, yaitu uji coba per blok sensor dan pengujian keseluruhan system. Pengujian per-blok sensor bertujuan untuk mengukur tingkat akurasi sensor yang digunakan. Sedangkan pengujian keseluruhan system untuk mendeteksi performa alat secara keseluruhan.

Pengujian per-blok sensor

Uji Coba Sensor Suhu DS18B20

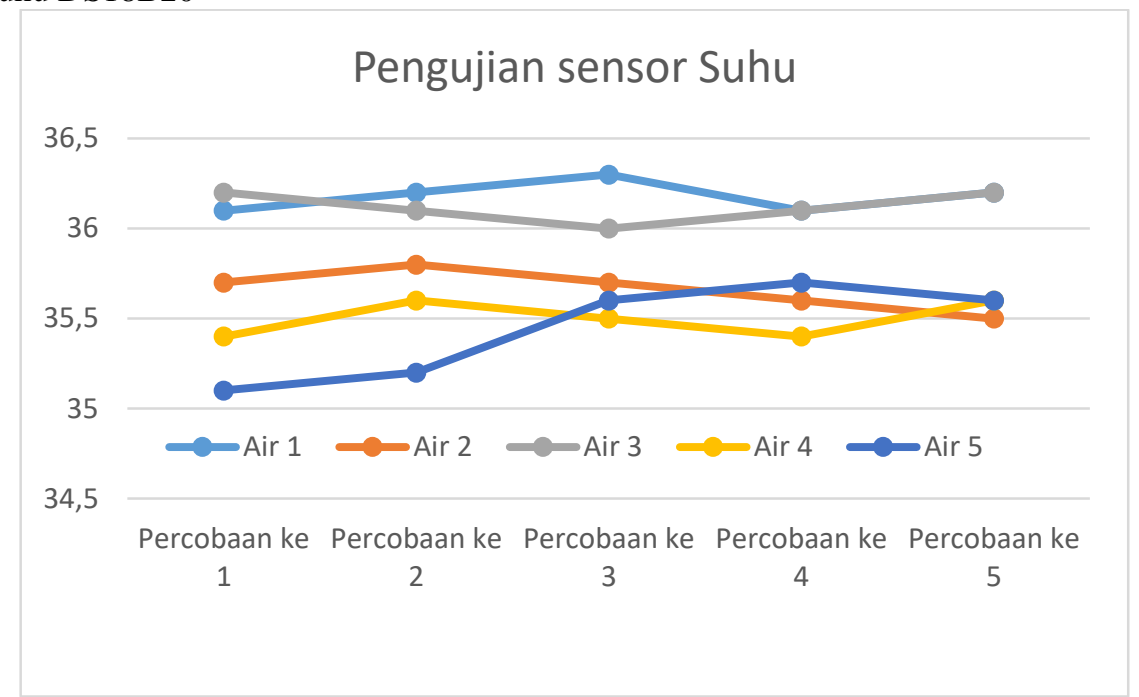

Gambar 6. Grafik pengujian sensor suhu

Gambar 6 adalah grafik hasil pengujian DS18B20. Pengujian dilaksanakan 5 kali menggunakan sensor yang sama dan kondisi suhu air yang berbeda pada setiap pengujian. Bisa dilihat pada percobaan pertama sensor suhu pertama mendeteksi suhu $36.1 \mathrm{oC}$, pada pengujian kedua $36.2 \mathrm{oC}$, pada pengujian ketiga $36.3 \mathrm{oC}$, pengujian keempat $36.1 \mathrm{oC}$ dan pengujian kelima $36.2 \mathrm{oC}$. Pada pengujian tersebut didapatkan data suhu air hasil pengujian sensor dimana suhu air tersebut memiliki selisih rata-rata 0.2 oC. dengan rata-rata selisih yang kecil maka sensor bisa dinyatakan akurat.

\section{Pengujian sensor tds}

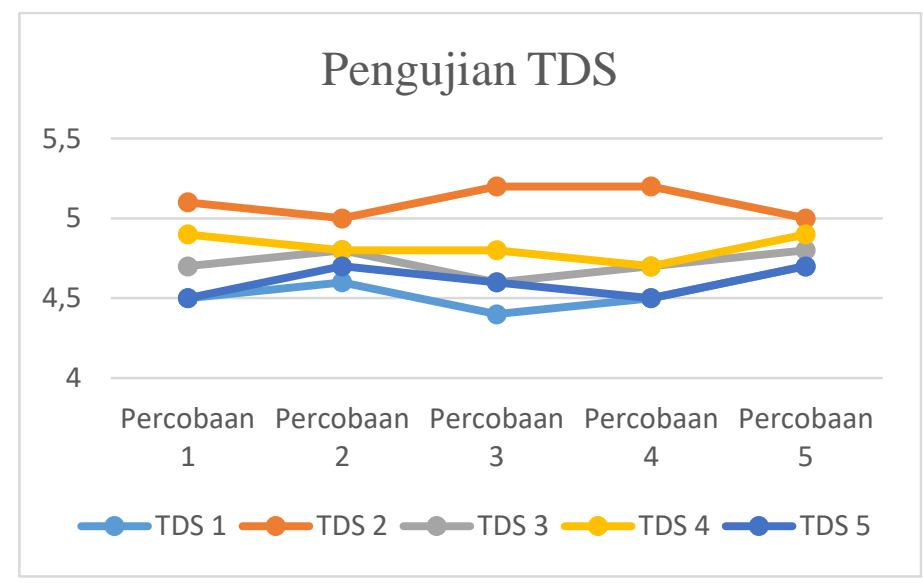

Gambar 7. Grafik Pengujian Sensor TDS

Gambar 7 adalah grafik pengujian sensor TDS. Pengujian dilakukan sebanyak lima kali dengan sensor yang sama tetapi dengan air yang berbeda pada setiap pengujian. Pada percobaan pertama sensor TDS mengeluarkan tegangan sebesar $4.5 \mathrm{~V}$, percobaan kedua sebesar $4.6 \mathrm{~V}$, percobaan ketiga $4.4 \mathrm{~V}$, percobaan keempat $4.5 \mathrm{~V}$, dan percobaan 
Procedia of Engineering and Life Science Vol. 1. No. 2 Juni 2021

Seminar Nasional \& Call Paper Fakultas Sains dan Teknologi (SENASAINS 2nd)

Universitas Muhammadiyah Sidoarjo

kelima 4.7 Volt. Pada grafik diatas diperoleh data pengujian dengan rata-rata selisih 0.1 dan $0.2 \mathrm{~V}$ pada air yang sama. Dengan data demikian maka sensor TDS bisa dinyatakan akurat.

Pengujian Sensor PH

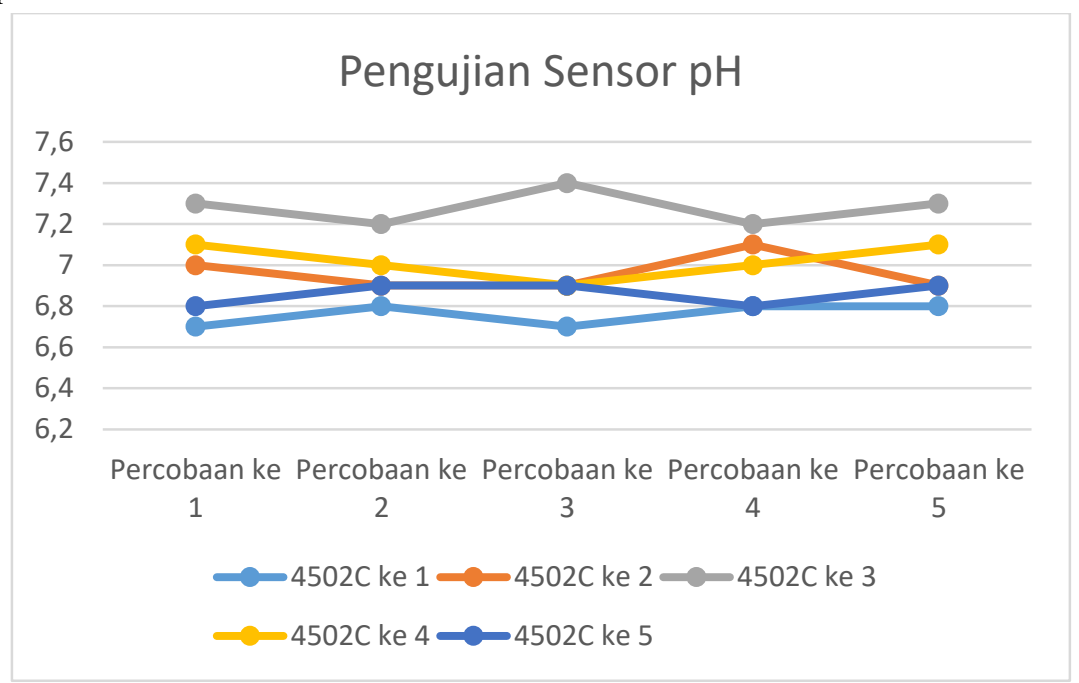

Gambar 8. Grafik Pengujian Sensor pH

Gambar 8 adalah grafik hasil pengujian sensor $\mathrm{pH}$, pengujian dilakukan menggunakan satu sensor yang sama tetapi dengan lima kondisi air yang berbeda. Pada percobaan pertama sensor $\mathrm{pH}$ membaca nilai $\mathrm{pH}$ sebesar 6.5, pada percobaan kedua sebesar 6.8, percobaan ketiga sebesar 6.7, percobaan keempat dan kelima mendeteksi nilai $\mathrm{pH}$ sebesar 6.8. dari uji coba diatas terdapat selisih pengujian 0.1 sampai 0.2. dengan nilai selisih pengujian sekecil itu maka sensor $\mathrm{pH}$ bisa dinyatakan cukup akurat.

\section{Pengujian keseluruhan}

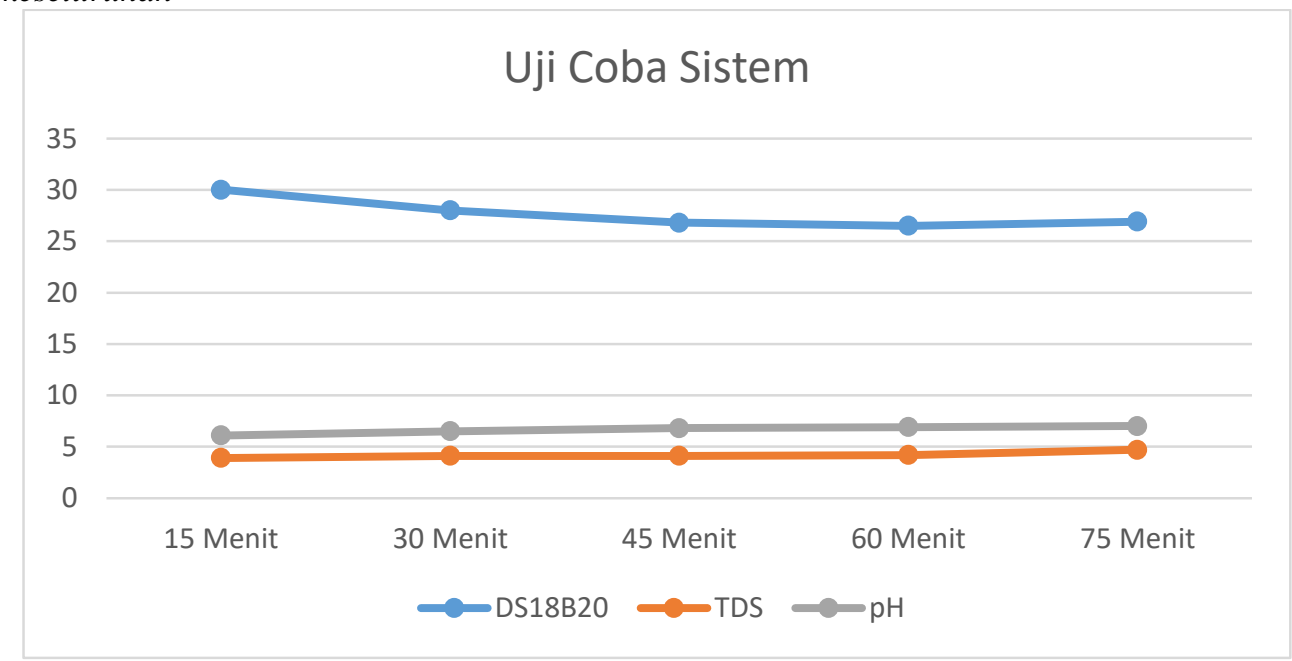

Gambar 9. Grafik Pengujian Sistem

Tabel 1. Hasil Pengujian Keseluruhan Sistem

\begin{tabular}{|l|l|l|l|l|}
\hline No & Durasi & DS18B20 & TDS & pH \\
\hline 1 & 15 Menit & 30 & 3.9 & 6.1 \\
\hline 2 & 30 Menit & 28 & 4.1 & 6.5 \\
\hline 3 & 45 Menit & 26.8 & 4.1 & 6.8 \\
\hline 4 & 60 Menit & 26.5 & 4.2 & 6.9 \\
\hline 5 & 75 Menit & 26.9 & 4.7 & 7 \\
\hline
\end{tabular}

Gambar 9 dan Tabel 1 adalah data hasil pengujian secara keseluruhan pada system. Pengambilan data dilakukan selama 75 menit. Pengambilan data dilakukan pada saat 15 menit pertama saat alat mulai bekerja. Pada 15 menit 
pertama sensor Suhu mendeteksi suhu sebesar 30 oC, sensor TDS mendeteksi tegangan sebesar $3.9 \mathrm{~V}$ dan sensor $\mathrm{pH}$ mendeteksi kadar keasaman air adalah 6.1. pada 15 menit pertama adalah fase dimana alat melakukan start pengkondisian air akuarium. Pada menit ke 30 sensor DS18B20 mendeteksi suhu sebesar 28 oC, sensor TDS 4.1V dan sensor pH 6.5. pada menit ke 30 kondisi air mulai memasuki skala kondisi air ideal yang diinginkan. Pada menit ke 45 sensor suhu mendeteksi suhu air sebesar $26.8 \mathrm{oC}$, sensor TDS $26.8 \mathrm{~V}$, sensor pH sebesar 6.8. pada durasi 45 menit kondisi air telah masuk pada skala air yang ideal untuk ikan guppy. Pada menit ke 60 air bersuhu 26.5 oC, TDS bernilai $4.2 \mathrm{~V}$, pH air 6.9. pada menit ke 60 air masih dalam posisi ideal untuk ikan guppy. Pada menit ke 75 air memiliki suhu 26.9 oC, TDS $4.7 \mathrm{~V}$, pH 7. Pada menit ke 75 kondisi air masih stabil pada kondisi yang ideal untuk ikan guppy.

Data yang didapat akan disimpan pada server thingspeak, jadi untuk monitoring bisa dilakukan secara realtime pada server thingspeak melalui aplikasi yang bisa dibuat dengan MIT. Data yang dideteksi oleh sensor akan disimpan dan diupdate setiap 10 detik.

\section{KESIMPULAN}

Dari hasil dan analisis secara umum dapat disimpulkan bahwa alat yang dirancang bisa memonitoring kualita air akuarium secara optimal pada kondisi secara ideal untuk ikan guppy. Air akuarium mengalami peningkatan kualitas dan mampu menjaga kualitas air akuarium dengan skala suhu diantara 23-27 oC, tingkat kekeruhan air dengan skala 0-25 NTU dan nilai pH air dengan skala 6.5-7.5. Dengan kondisi air yang mengalami peningkatan, ikan guppy menjadi lebih aktif berenang.

\section{REFERENSI}

[1] Septiyan.R, Rusliadi, and Iskandar.P, "The Effect Of Different Feeding On Growth And Color Of Guppy Fish (Poecilia Reticulata),” J. Onine Mhs. Bid. Perikan. dan Ilmu Kelaut., vol. 4, no. 2, pp. 1-7, 2017.

[2] I. Publication and P. D. F. Pack, "SYSTEM IDENTIFICATION OF BLDC MOTOR AND OPTIMIZATION SPEED CONTROL SYSTEM IDENTIFICATION OF BLDC MOTOR."

[3] M. F. Fish, "REALISASI SISTEM KENDALI AKUARIUM OTOMATIS PADA PEMELIHARAAN IKAN HIAS AIR TAWAR The Realization of Automatic Aquarium Control System at Maintaining Freshwater Fish," vol. 6, no. 3, pp. 10128-10137, 2019.

[4] D. R. Pratama, H. Wijayanti, and H. Yulianto, "PENGARUH WARNA WADAH PEMELIHARAAN TERHADAP PENINGKATAN INTENSITAS WARNA IKAN GUPPY (Poecilia reticulata)," e-Jurnal Rekayasa dan Teknol. Budid. Perair., vol. 7, no. 1, p. 775, 2018, doi: 10.23960/jrtbp.v7i1.p775-782.

[5] K. S. Budi and Y. Pramudya, "PENGEMBANGAN SISTEM AKUISISI DATA KELEMBABAN DAN SUHU DENGAN MENGGUNAKAN SENSOR DHT11 DAN ARDUINO,” vol. VI, pp. 47-54, 2017.

[6] I. ANSHORY, I. ROBANDI, J. Jamaaluddi, A. FUDHOLI, and WIRAWAN, "Transfer function modeling and optimization speed response of bldc motor e-bike using intelligent controller," J. Eng. Sci. Technol., vol. 16, no. 1, pp. 305-324, 2021.

[7] H. Eka Putra, M. Jamil, and S. Lutfi, "Smart Akuarium Berbasis Iot Menggunakan Raspberry Pi 3," JIKO (Jurnal Inform. dan Komputer), vol. 2, no. 2, pp. 60-66, 2019, doi: 10.33387/jiko.v2i2.1179.

[8] M. Yuyun and Q. Hadiana, "PROGRAM KREATIVITAS MAHASISWA “ SMART AQUARIUM 'UARIUM" Akuarium dengan Sistem Geobiofilter untuk Peningka gkatan Efisiensi Penggunaan Air BIDANG KEGIATAN : LEMBAR PENGESAHAN PKM-KC," 2010.

[9] I. A. Rozaq, N. Yulita, D. Setyaningsih, and K. Kunci, "Karakterisasi dan kalibarasi sensor ph menggunakan arduino uno 12," Sendi_U, pp. 978-979, 2018.

[10] O. K. Sulaiman and A. Widarma, "Sistem Internet of Things (Iot) Berbasis Cloud Computing Dalam Campus Area Network," 2017, doi: 10.31227/osf.io/b6m79.

[11] J. T. Komputer, "IMPLEMENTASI MODUL WIFI NODEMCU ESP8266 UNTUK SMART HOME Mochamad Fajar Wicaksono Mochamad Fajar Wicaksono,” vol. 6, no. 1, pp. 9-14, 2017.

[12] S. W. Mudjanarko, "Pemanfaatan Internet of Things (Iot) Sebagai Solusi Manejemen Transportasi Kendaraan Sepeda Motor," no. October, 2017, doi: 10.31219/osf.io/6ue4b.

[13] I. Anshory, D. Hadidjaja, and I. Sulistiyowati, "Monitoring Perubahan Tegangan dan Pemodelan Matematika Fungsi Transfer Motor BLDC Dengan System Identification Toolbox Program Studi Teknik Elektro, Fakultas Saintek , Universitas Muhammadiyah Sidoarjo,” pp. 18-25. 